\title{
Evolution of Telepathology: A Comprehensive Analysis of Global Telepathology Literature Between 1986 and 2017
}

\author{
Engin ŞENEL' ${ }^{10}$, Yılmaz BAŞ²
}

Department of 'Dermatology and ${ }^{2}$ Pathology, Hitit University Faculty of Medicine, ÇORUM, TURKEY

\begin{abstract}
Objective: Telepathology is an application of telemedicine providing remote evaluation and consultation of digital pathology images and can be used for educational or experimental purposes. Bibliometrics is a statistical discipline investigating publication patterns and trends in a certain academic field. Although bibliometric and scientometric studies are becoming increasingly popular, the relevant literature contains only one limited article related to telepathology. The aim of our study was to perform a holistic bibliometric analysis of the telepathology literature.
\end{abstract}

Material and Method: Since the first article on telepathology was published in 1986, we included all indexed articles retrieved from Web of Science databases between 1986 and 2017.

Results: We found that the USA covering $43.01 \%$ of all literature was the leading country in the telepathology field and was followed by Germany, Italy and the UK ( $n=120,90$ and 83, respectively). The countries with the most contributions were located in the continents of Europe and North America. The most productive source titles were Human Pathology, Journal of Telemedicine and Telecare, and Modern Pathology. Harvard University ranked first with 59 articles. The most commonly used keywords of the telepathology literature were "telepathology", "telemedicine", "digital pathology", "virtual microscopy" and "telecytology". We noted that all of the ten countries with the most contributions were in the developed category of UN classification and all twenty of the most productive institutions were from developed countries.

Conclusion: We suggest that researchers from developing and least developed countries should be encouraged to carry out novel studies since telemedicine is a required and promising technology for rural developing or least developed areas in which access to health care is difficult.

Key Words: Telepathology, Telemedicine, Bibliometrics, Scientometrics, Publication trend

\section{INTRODUCTION}

Telemedicine is the process of transmitting medical information and the application of medical services using communication technologies (1). The World Health Organization (WHO) defines telemedicine as "..the delivery of healthcare services, where distance is a critical factor, by all healthcare professionals using information and communication technologies for the exchange of valid information for diagnosis, treatment and prevention of disease and injuries, research and evaluation, and for the continuing education of healthcare providers, all in the interests of advancing the health of individuals and their communities..." (2). Telepathology is a relatively novel practice of telemedicine providing remote evaluation of digital pathology images. Telepathology is defined by the American Telemedicine Association as "the electronic multimedia communication across a network of pathologyrelated information, between two or more locations for use between pathologists and/or qualified laboratory personnel, and may include involvement by clinicians and/or patients" (3). Telepathology can be used for educational or experimental purposes, primary diagnosis and secondary consultation in all divisions of pathology including histocytopathology, autopsy, and surgical and anatomical pathology (4).

Bibliometrics provides holistic data on publication trends and patterns and is described as "science of science" (5). Although scientometric and bibliometric studies have been popular recently, only one study relevant to telepathology has been reported so far to the best of our knowledge. To fully utilize the advantages of telepathology, individual feasibility studies are necessary, as data analysis, organizations, societies and infrastructures (6). Our study aims to present a comprehensive bibliometric analysis of the literature of telepathology.

\section{MATERIAL and METHOD}

All data of our study was retrieved from four databases of Web of Science (WOS, Thomson Reuters, New York, NY, USA) titled Web of Science Core Collection, Korean Journal 
Database, SciELO Citation Index and Russian Science Citation Index. We used the keywords of "telepathology" and "telecytology" to search the WoS database. All documents produced between 1986 and 2017 were included. Since the first article of telepathology literature was published in 1986, we chose 1986 as the starting year. We used GunnMap to generate a global productivity map (7). VOSviewer was the freeware tool used for creating scientometric networks in our study (8). We used the United Nations (UN) system for country classification (9).

\section{RESULTS}

\section{General Feature of the Literature}

Our search yielded 1109 articles in the telepathology literature between 1986 and 2017. Only 237 documents (21.37\%) were open access. The peak year for number of publications was 2012 with 83 articles. No pattern was detected in the progress of the total number of publications by year. No items were produced in the years of 1988, 1990 and 1992 (Figure 1). English is the main language of the literature $(94.91 \%)$ followed by German and French (2.43 and $2.08 \%$, respectively). The most studied research areas were found to be health care sciences, telecommunications, pathology, computer science and oncology $(68.89,63.12$, $55.45,42.38$ and $39.58 \%$, respectively; Table I). The most common document types in the literature were original article, meeting abstract and review $(72.77,28.40$ and $18.12 \%$, respectively; Table II).
Table I: The most studied research areas of the telepathology literature between 1986 and 2017.

\begin{tabular}{lcc}
\hline Research Area & $\begin{array}{c}\text { Record } \\
\text { Count }\end{array}$ & $\begin{array}{c}\text { \% of 1109 } \\
\text { articles }\end{array}$ \\
\hline Health Care Sciences & 764 & 68.89 \\
\hline Telecommunications & 700 & 63.12 \\
\hline Pathology & 615 & 55.45 \\
\hline Computer Science & 470 & 42.38 \\
\hline Oncology & 439 & 39.58 \\
\hline Mathematical Computational & 370 & 33.36 \\
Biology & 326 & 29.39 \\
\hline Microscopy & 300 & 27.05 \\
\hline Medical Laboratory Technology & 297 & 26.78 \\
\hline Science Technology & 279 & 25.15 \\
\hline General Internal Medicine & 278 & 25.07 \\
\hline Radiology & 247 & 22.27 \\
\hline Surgery & 227 & 20.47 \\
\hline Imaging Science & 205 & 18.48 \\
\hline Engineering & 197 & 17.76 \\
\hline Medical Informatics & 188 & 16.95 \\
\hline Cell Biology & 143 & 12.89 \\
\hline Information Science & 126 & 11.36 \\
\hline Dermatology & 126 & 11.36 \\
\hline Educational Research & 122 & 11.01 \\
\hline Mathematics & $\mathbf{1 1 0 9}$ & $\mathbf{1 0 0}$ \\
\hline Total & &
\end{tabular}

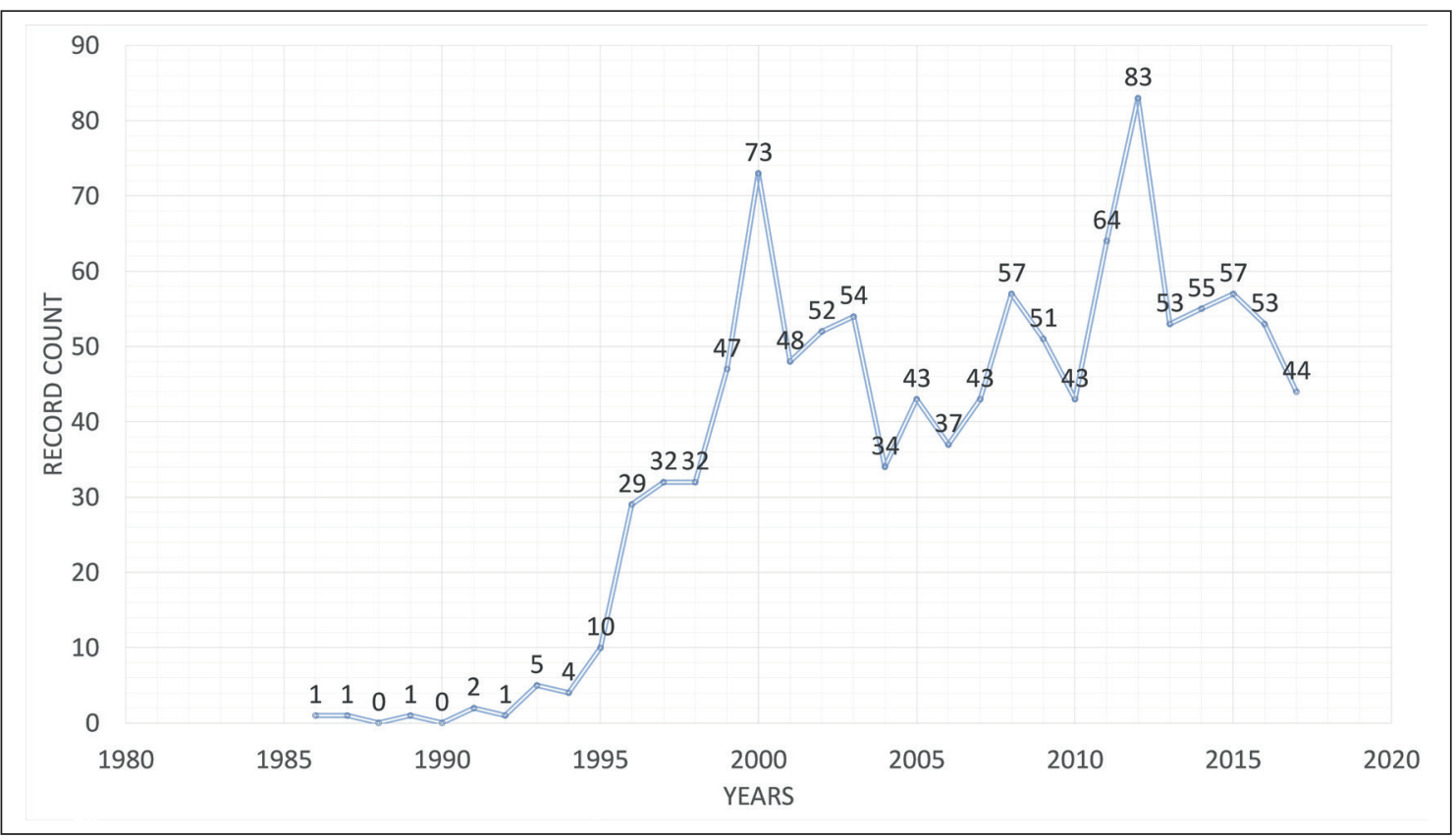

Figure 1: Number of telepathology publications by year. 


\section{Productivity of Countries, Authors, Journals and Institutions}

The USA, covering $43.01 \%$ of the literature, was detected to rank first among countries with 477 articles, followed by Germany, Italy and the UK ( $\mathrm{n}=120,90$ and 83, respectively;

Table II: Document types published in the telepathology literature.

\begin{tabular}{lcc}
\hline Document Types & Record Count & $\begin{array}{c}\text { \% of 1109 } \\
\text { articles }\end{array}$ \\
\hline Original Article & 807 & 72.77 \\
\hline Meeting Abstract & 315 & 28.40 \\
\hline Abstract & 201 & 18.12 \\
\hline Review & 147 & 13.25 \\
\hline Letter & 52 & 4.69 \\
\hline Editorial & 38 & 3.43 \\
\hline Clinical Trial & 23 & 2.07 \\
\hline News & 8 & 0.72 \\
\hline Case Report & 7 & 0.63 \\
\hline Correction & 3 & 0.27 \\
\hline Book & 2 & 0.18 \\
\hline Reference Material & 2 & 0.18 \\
\hline Biography & 1 & 0.09 \\
\hline Unspecified / Other & 358 & 32.28 \\
\hline Total & $\mathbf{1 1 0 9}$ & $\mathbf{1 0 0}$ \\
\hline
\end{tabular}

Figure 2). China stood out among developing countries according to the UN classification with 18 articles (3.07\%) followed by Brazil, India and Colombia (1.44, 1.26 and $0.81 \%$, respectively). From the underdeveloped (least developed) countries, Benin, Burundi, Congo, Rwanda, Senegal, Sudan and Zambia produced one article each.

The countries contributing the most countries were located in the continents of Europe and North America (Figure 3). Weinstein RS was the most prolific author with 44 papers (3.97\%, Table III). The source titles with the most contributions were Human Pathology, Journal of Telemedicine and Telecare and Modern Pathology ( $\mathrm{n}=$ 80, 69 and 56 articles, respectively; Table IV). The most productive meeting in this field was the $10^{\text {th }}$ European Congress on Telepathology and the $4^{\text {th }}$ International Congress on Virtual Microscopy with 20 proceedings (Table V). Harvard University was the leading institution with 59 documents followed by the University of Arizona, Pennsylvania Commonwealth System of Higher Education, and the University of Pittsburgh ( $\mathrm{n}=52,50$ and 48 items, respectively; Table VI).

\section{Citations, Keywords and Bibliometric Network Analyses}

The h-index is a calculated metric value to measure productivity and citation impact in a certain area. The h-index of telepathology literature was 52 . The total number of citations was 14,911 (8,997 without self-citations) and the average number of citations per item were 13.45.

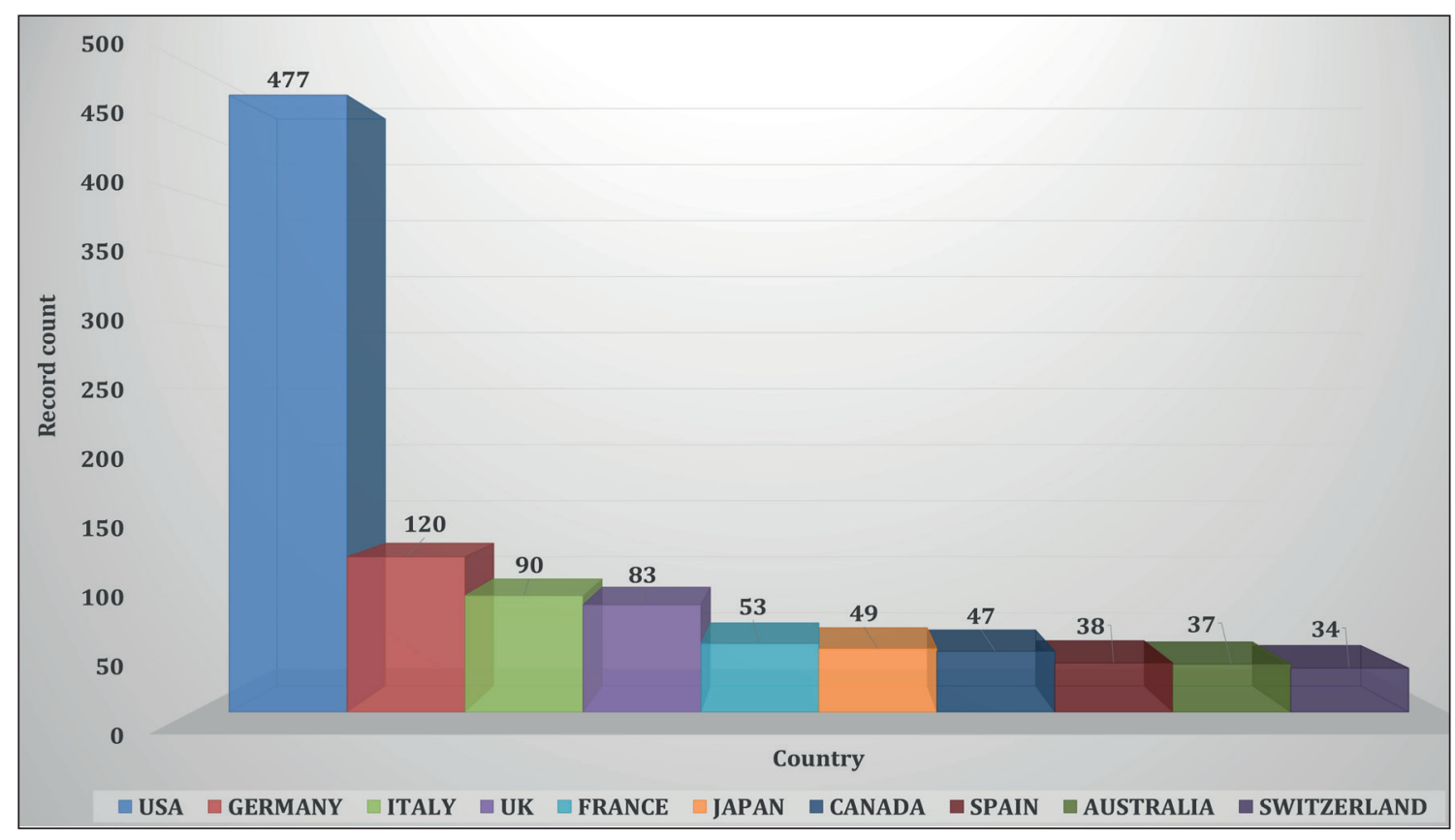

Figure 2: Top ten countries publishing telepathology articles between 1986 and 2017. 
Table III: The 20 most prolific authors of the telepathology literature between 1986 and 2017.

\begin{tabular}{lcc}
\hline Author & Record Count & \% \\
\hline Weinstein RS & 44 & 3.97 \\
\hline Della Mea V & 29 & 2.61 \\
\hline Krupinski EA & 28 & 2.52 \\
\hline Kayser K & 27 & 2.43 \\
\hline Pantanowitz L & 23 & 2.07 \\
\hline Beltrami CA & 19 & 1.71 \\
\hline Kayser G & 18 & 1.62 \\
\hline Evans AJ & 16 & 1.44 \\
\hline Giansanti D & 16 & 1.44 \\
\hline Graham AR & 16 & 1.44 \\
\hline Parwani AV & 16 & 1.44 \\
\hline Yagi Y & 16 & 1.44 \\
\hline Oberholzer M & 15 & 1.35 \\
\hline Giovagnoli MR & 14 & 1.26 \\
\hline Bhattacharyya AK & 13 & 1.17 \\
\hline Hufnagl P & 13 & 1.17 \\
\hline Schrader T & 13 & 1.17 \\
\hline Tetu B & 13 & 1.17 \\
\hline Brauchli K & 12 & 1.08 \\
\hline Soyer HP & 12 & 1.08 \\
\hline
\end{tabular}

Table IV: The journals with the most contributions to the telepathology literature.

\begin{tabular}{lcc}
\hline Journals & $\begin{array}{c}\text { Record } \\
\text { Count }\end{array}$ & $\begin{array}{c}\text { \% of 1109 } \\
\text { items }\end{array}$ \\
\hline Human Pathology & 80 & 7.21 \\
\hline Journal of Telemedicine and Telecare & 69 & 6.22 \\
\hline Modern Pathology & 56 & 5.05 \\
\hline Laboratory Investigation & 53 & 4.78 \\
\hline Diagnostic Pathology & 49 & 4.42 \\
\hline $\begin{array}{l}\text { Archives of Pathology \& Laboratory } \\
\text { Medicine }\end{array}$ & 42 & 3.79 \\
\hline Analytical Cellular Pathology & 37 & 3.34 \\
\hline Telemedicine Journal and e-Health & 35 & 3.16 \\
\hline Studies in Health Technology and & 28 & 2.52 \\
\hline Informatics & 27 & 2.43 \\
\hline American Journal of Clinical Pathology & 25 & 2.25 \\
\hline Histopathology & 21 & 1.89 \\
\hline Virchows Archiv & 19 & 1.71 \\
\hline Journal of Clinical Pathology & 19 & 1.71 \\
\hline Journal of Pathology & 12 & 1.08 \\
\hline Acta Cytologica & 12 & 1.08 \\
\hline Journal of the American Academy \\
of Dermatology
\end{tabular}

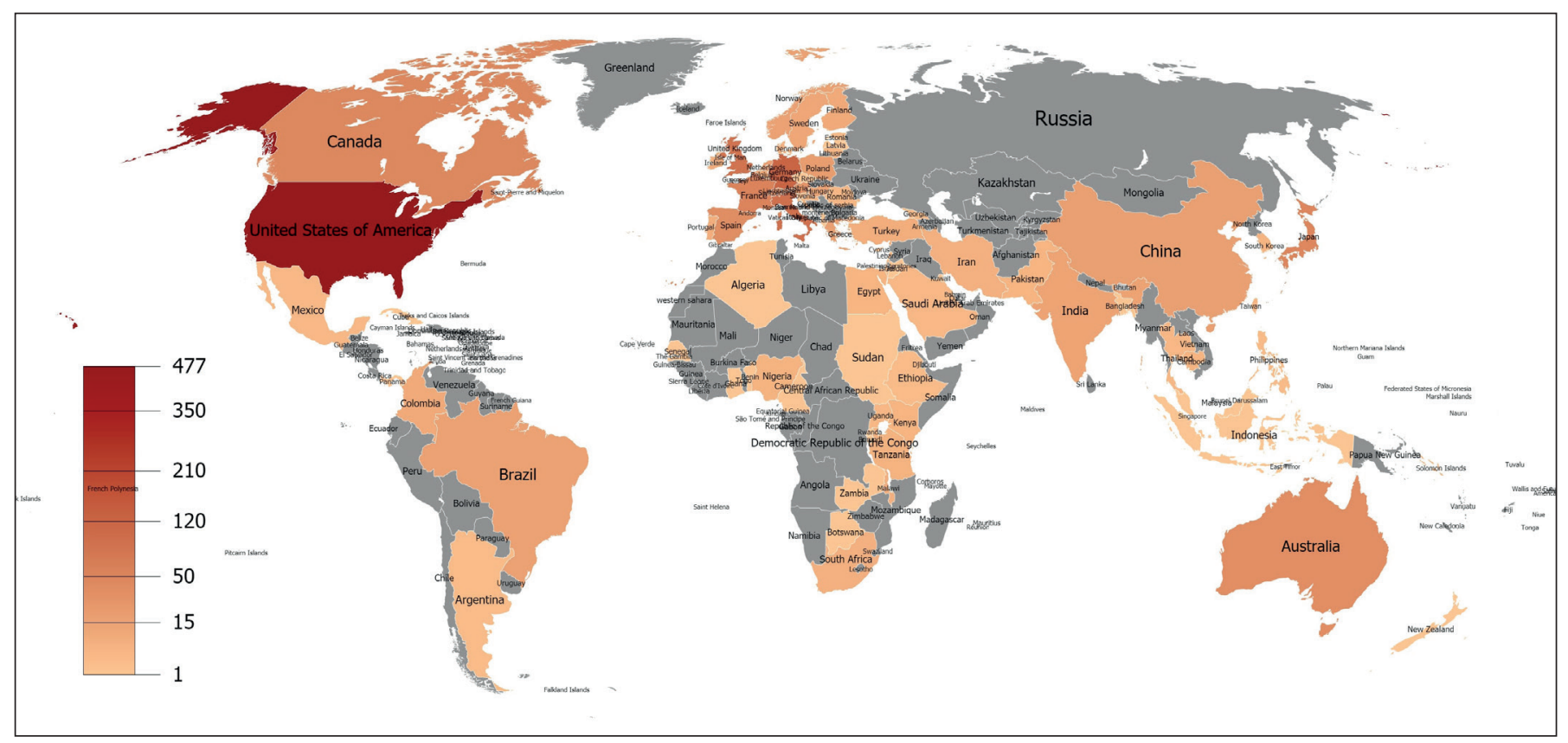

Figure 3: Publication density of world countries in the telepathology field. 
The most cited article was an original article titled "Telemedicine Technology and Clinical Applications" published in 1995 by Perednia and Allen (Table VII). This article did not only focus on telepathology and mentioned telepathology as an application of store-and-forward telemedicine (10). The most cited document focusing on telepathology was an original article titled "Overview of telepathology, virtual microscopy, and whole slide imaging: prospects for the future" published in 2009 by Weinstein RS who is the most prolific author of telepathology literature, and was cited 146 times. The article presented information relevant to fourth-generation telepathology systems, so-called virtual slide telepathology systems used for educational purposes (11).

Table V: The meetings or conferences in which the most documents on telepathology were presented.

\begin{tabular}{lcc}
\hline Meeting Titles & $\begin{array}{c}\text { Record } \\
\text { Count }\end{array}$ & $\begin{array}{c}\text { \% of } \\
\mathbf{3 7 2 8 3}\end{array}$ \\
\hline $10^{\text {th }}$ European Congress on Telepathology and 4th International Congress on Virtual Microscopy & 20 & 1.80 \\
\hline $102^{\text {nd }}$ Annual Meeting of The United States and Canadian Academy of Pathology & 14 & 1.26 \\
\hline $101^{\text {st }}$ Annual Meeting of The United States and Canadian Academy of Pathology & 10 & 0.90 \\
\hline $106^{\text {th }}$ Annual Meeting of The United States and Canadian Academy of Pathology & 9 & 0.81 \\
\hline $92^{\text {nd }}$ Annual Meeting of The United States and Canadian Academy of Pathology & 8 & 0.72 \\
\hline $97^{\text {th }}$ Annual Meeting of The United States and Canadian Academy of Pathology & 8 & 0.72 \\
\hline $9^{\text {th }}$ European Congress on Telepathology and 3RD International Congress on Virtual Microscopy & 8 & 0.72 \\
\hline $103^{\text {rd }}$ Annual Meeting of The United States and Canadian Academy of Pathology & 6 & 0.54 \\
\hline $104^{\text {th }}$ Annual Meeting of The United States and Canadian Academy of Pathology & 6 & 0.54 \\
\hline $11^{\text {th }}$ International Conference on Informatics Management and Technology in Healthcare & 6 & 0.54 \\
\hline
\end{tabular}

Table VI: The 20 most productive institutions in the telepathology literature between 1986 and 2017.

\begin{tabular}{lccc}
\hline Institutions & Country & Record Count & $\%$ \\
\hline Harvard University & USA & 59 & 5.32 \\
\hline University of Arizona & USA & 52 & 4.69 \\
\hline Pennsylvania Commonwealth System of Higher Education & USA & 50 & 4.51 \\
\hline University of Pittsburgh & USA & 48 & 4.33 \\
\hline VA Boston Healthcare System & USA & 42 & 3.79 \\
\hline Free University of Berlin & Germany & 34 & 3.07 \\
\hline Charité Medical University of Berlin & Germany & 32 & 2.89 \\
\hline Humboldt University of Berlin & Germany & 32 & 2.89 \\
\hline Massachusetts General Hospital & USA & 29 & 2.61 \\
\hline University of California System & USA & 29 & 2.61 \\
\hline University of Udine & Italy & 29 & 2.61 \\
\hline United States Department of Defense & USA & 25 & 2.25 \\
\hline Assistance Publique - Hôpitaux de Paris & France & 21 & 1.89 \\
\hline University of Toronto & Canada & 21 & 1.89 \\
\hline University of Basel & Switzerland & 20 & 1.80 \\
\hline University of London & UK & 18 & 1.62 \\
\hline Johns Hopkins University & USA & 17 & 1.53 \\
\hline University Health Network & Canada & 17 & 1.53 \\
\hline Cedars-Sinai Medical Center & USA & 16 & 1.44 \\
\hline Istituto Superiore di Sanita & Italy & 16 & 1.44 \\
\hline
\end{tabular}


Table VII: The most cited articles in telepathology literature by decades.

\begin{tabular}{|c|c|c|c|c|}
\hline Article & Author(s) & Year & $\begin{array}{c}\text { Total } \\
\text { Citation } \\
\end{array}$ & $\begin{array}{c}\text { Average Citations } \\
\text { per Year }\end{array}$ \\
\hline $\begin{array}{l}\text { Telemedicine Technology and Clinical- } \\
\text { Applications }\end{array}$ & Perednia, DA; Allen, A & 1995 & 387 & 15.48 \\
\hline $\begin{array}{l}\text { Overview of Telepathology, Virtual } \\
\text { Microscopy, and whole Slide Imaging: } \\
\text { Prospects for the Future }\end{array}$ & $\begin{array}{l}\text { Weinstein, Ronald S.; } \\
\text { Graham, Anna R.; Richter, } \\
\text { Lynne C.; et al. }\end{array}$ & 2009 & 149 & 13.55 \\
\hline $\begin{array}{l}\text { Validating whole Slide Imaging for Diagnostic } \\
\text { Purposes in Pathology Guideline from The } \\
\text { College of American Pathologists Pathology } \\
\text { and Laboratory Quality Center }\end{array}$ & $\begin{array}{l}\text { Pantanowitz, Liron; Sinard, } \\
\text { John H.; Henricks, Walter H.; } \\
\text { et al. }\end{array}$ & 2013 & 131 & 18.71 \\
\hline $\begin{array}{l}\text { Eye-Movement Study and Human } \\
\text { Performance Using Telepathology Virtual } \\
\text { Slides. Implications for Medical Education and } \\
\text { Differences with Experience }\end{array}$ & $\begin{array}{l}\text { Krupinski, Elizabeth A.; } \\
\text { Tillack, Allison A.; Richter, } \\
\text { Lynne; et al. }\end{array}$ & 2006 & 125 & 8.93 \\
\hline $\begin{array}{l}\text { Critical Comparison of } 31 \text { Commercially } \\
\text { Available Digital Slide Systems in Pathology }\end{array}$ & $\begin{array}{l}\text { Garcia Rojo, Marcial; Bueno } \\
\text { Garcia, Gloria; Peces Mateos, } \\
\text { Carlos; et al. }\end{array}$ & 2006 & 122 & 8.71 \\
\hline $\begin{array}{l}\text { Robust Segmentation of Overlapping Cells in } \\
\text { Histopathology Specimens Using Parallel Seed } \\
\text { Detection and Repulsive Level Set }\end{array}$ & $\begin{array}{l}\text { Qi, Xin; Xing, Fuyong; Foran, } \\
\text { David J.; et al. }\end{array}$ & 2012 & 121 & 15.13 \\
\hline $\begin{array}{l}\text { Telepathology Overview: From Concept to } \\
\text { Implementation }\end{array}$ & Weinstein, RS; Descour, MR & 2012 & 119 & 6.26 \\
\hline $\begin{array}{l}\text { Telepathology and the Networking of } \\
\text { Pathology Diagnostic Services }\end{array}$ & $\begin{array}{l}\text { Weinstein, RS; Bloom, KJ; } \\
\text { Rozek, LS }\end{array}$ & 1987 & 111 & 3.36 \\
\hline $\begin{array}{l}\text { Digital pathology: current status and future } \\
\text { perspectives }\end{array}$ & $\begin{array}{l}\text { Al-Janabi, Shaimaa; Huisman, } \\
\text { Andre; Van Diest, Paul J. }\end{array}$ & 2012 & 110 & 13.75 \\
\hline Telepathology: A ten-year progress report & $\begin{array}{l}\text { Weinstein, RS; Bhattacharyya, } \\
\text { AK; Graham, AR; et al. }\end{array}$ & 1997 & 109 & 4.74 \\
\hline
\end{tabular}

Table VIII: The 20 most used keywords in the telepathology literature.

\begin{tabular}{lll}
\hline \multicolumn{2}{c}{ Keyword (total link strength) } \\
\hline 1 & Telepathology (842) & 11 Frozen section (38) \\
\hline 2 & Telemedicine (333) & 12 Telehealth (64) \\
\hline 3 & Digital pathology (181) & 13 Telemicroscopy (49) \\
\hline 4 & Virtual microscopy (181) & 14 Surgical pathology (46) \\
\hline 5 & Telecytology (132) & 15 Teleradiology (39) \\
\hline 6 & Internet (90) & 16 Cytology (63) \\
\hline 7 & Pathology (119) & 17 Digital imaging (44) \\
\hline 8 & Whole-slide imaging (96) & 18 Diagnosis (46) \\
\hline 9 & Virtual slide(s) (89) & 19 Quality assurance (39) \\
\hline 10 & Diagnostic accuracy (53) & 20 Digital microscopy (35) \\
\hline & &
\end{tabular}

The most common keywords of the telepathology literature were "telepathology", "telemedicine", "digital pathology", "virtual microscopy" and "telecytology" (Table VIII). Bibliometric network analysis of the keywords revealed a "starburst pattern" in which keywords of "telepathology", "digital pathology" and "internet" were centered (Figure 4). As we analyzed the co-authorship among countries, it was found that the most collaborative countries were the USA with 377 documents and 6286 citations (total link strength, TLS=127) followed by Italy, the UK and Germany (TLS=79, 73 and 71, respectively; Figure 5).

\section{DISCUSSION}

The earliest telemedicine applications date back to the eighteenth and nineteenth centuries. In these centuries, patients wrote detailed letters containing medical histories 
and symptoms and sent them to specialist doctors by couriers, and doctors responded with the diagnosis, treatment plan and prescription (12). Willem Einthoven (1860-1927), a Dutch doctor and physiologist who invented the first electrocardiogram (ECG) transmitted ECGs of the patients from the hospital to an off-site laboratory by means of telegraph (13). The first remote assessment of medical images, reported in 1950, was performed between the Chester County Hospital and Philadelphia over a distance of twenty-eight miles via commercial telephone wires or radio and described as "telognosis" (14). In the late 1950s, National Aeronautics and Space Administration (NASA) initiated the Space Technology Applied to Rural Papago Advanced Health Care (STARPAHC) Project for telemedical consultation of people living in remote locations of Arizona's Papago Indian Reservation with little or no medical services. In 1964, a closed circuit television system was introduced between the Nebraska Psychiatric Institute and the Norfolk State Hospital 112 miles away to use telemedicine for neurologic and psychiatric evaluation of the patients (15).

The first recorded telepathology procedure was performed in the late 1960s between Massachusetts General Hospital and Logan Airport Medical Station in Boston via a realtime "television microscopy" service (16). Since this onset, the research area of telepathology has been growing into subfields. The first paper in the telepathology field was an editorial published in 1986 and titled "Prospects for Telepathology" by Ronald Weinstein. The author defined telepathology as "the practice of pathology by visualizing an indirect image on a television screen rather than viewing a specimen directly through a microscope...". Interestingly, there was no study on telepathology in the

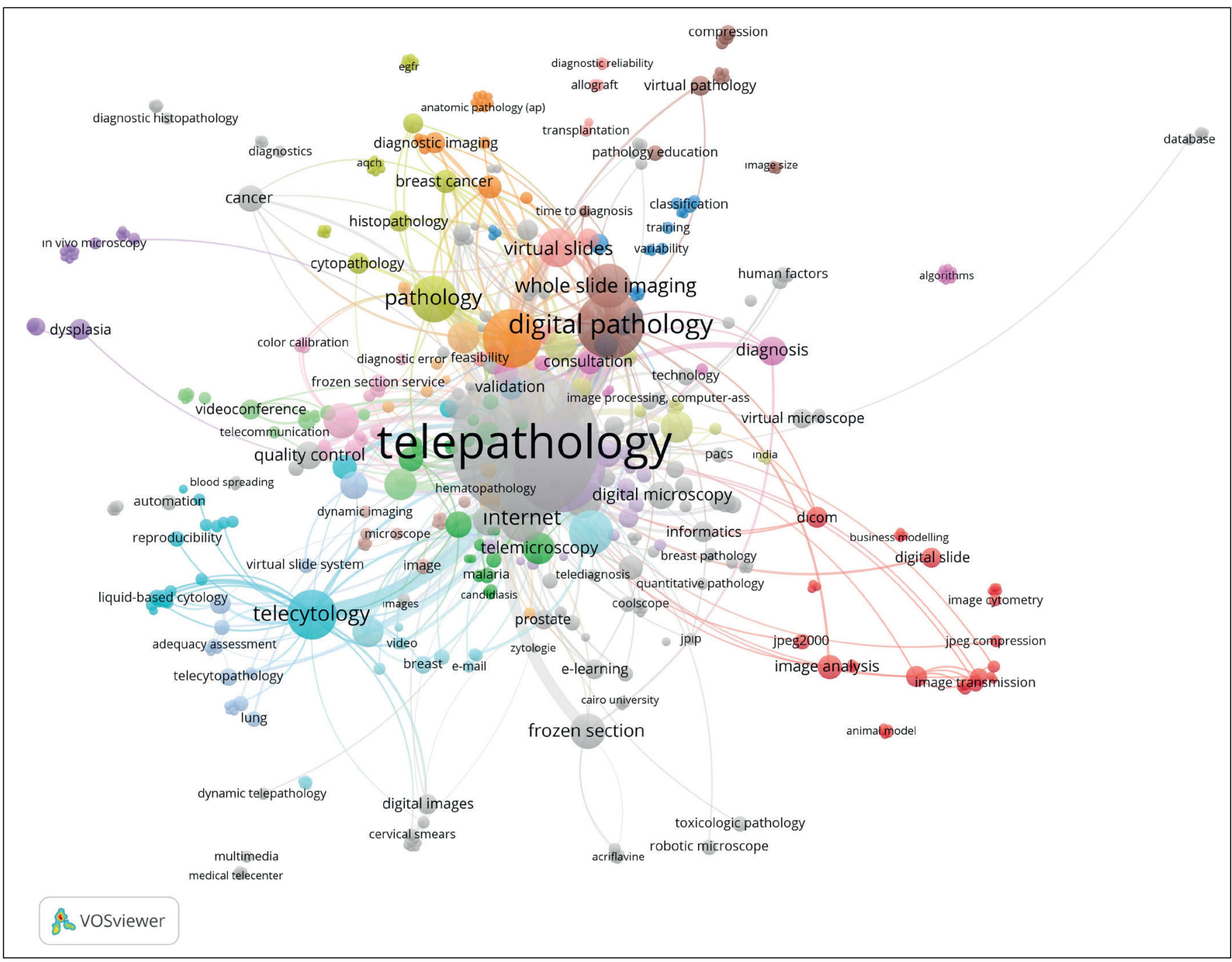

Figure 4: Bibliometric network of the most used keywords in the telepathology literature. 
medical literature prior to this definition. Weinstein predicted the future of computer technology perfectly and defined the level of development of telepathology at that time as "an embryonic stage of development" (16). Over the last 30 years, the generation of telepathology systems has improved rapidly with the evolution of digital microscopy: video-microscopy, robotic microscopy and the upgrade to virtual slide processing systems. This change is a revolution in the traditional pathology practice in today's computer age (17). Increased workload, case complexity, financial constraints, and staffing shortages justify wider implementations of digital pathology (6). The possibility to consult expert colleagues using telepathology, particularly for cases not requiring molecular investigations in external laboratories, may also permit significant financial savings, reduce the turnaround time, facilitate the international change of information, and support the sharing of even more cases (18).
Bibliometrics is a popular statistical application providing quantitative and qualitative analysis of a certain academic field (19). The term was coined by Alan Pritchard in the late 1960s as "an application of mathematics and statistical methods to books and other media of communication" although Siyali Ramamrita Ranganathana, who was a librarian and mathematician from India, created the principal ideas behind bibliometrics and scientometrics in the 1940s $(19,20)$. Bibliometric studies have become increasingly popular in the academic literature in the last decades, and a total of 8806 reports have been published in the time period of our study according to the WoS databases. Although the term of telepathology has been included in $\mathrm{MeSH}$ terminology since 1996, the scientific literature contained only one bibliometric study of telepathology. Della Mea reported the first and only bibliometric study in the telepathology literature in 2011 (21). The data of this study was extracted from PubMed and only 967 papers

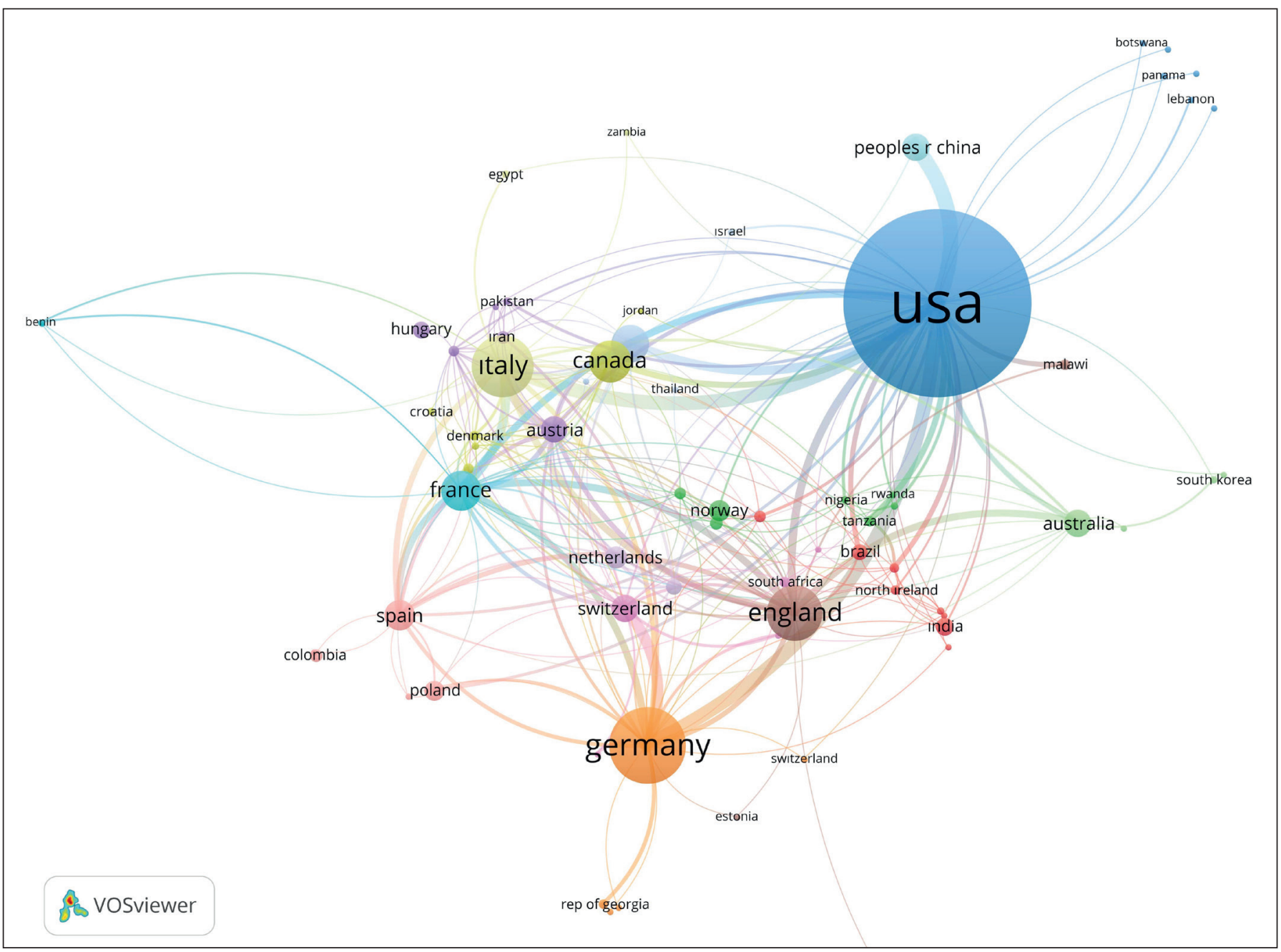

Figure 5: The most collaborative countries in the telepathology literature. 
published in 344 different journals from 34 countries were detected between 1986 and 2010. The USA was found to be the leading country as noted in our study with 310 articles (32.06\%) followed by Germany, Italy, UK and Japan ( $\mathrm{n}=81$, 46, 40 and 27 documents, respectively). The major journals in the telepathology field were Journal of Telemedicine and Telecare, Human Pathology and the Telemedicine Journal ( $\mathrm{n}=71,65$ and 27 items, respectively) (21).

In conclusion, we found that all ten of the most contributing countries were in developed category of UN classification although telemedicine is a required and promising technology for rural developing or least developed areas in which access to health care is difficult. Also, all twenty most productive institutions were from developed countries. We suggest that researchers from developing and least developed countries should be encouraged to carry out novel studies.

\section{CONFLICT of INTEREST}

The authors declare no conflict of interest.

\section{REFERENCES}

1. Şenel E. History of teledermatology: A technique of the future in dermatology. Skinmed. 2010;8(3):167-73.

2. Feroze K. Teledermatology in India: Practical implications. Indian J Med Sci. 2008;62:208-14.

3. Pare G, Meyer J, Trudel MC, Tetu B. Impacts of a large decentralized telepathology Network in Canada. Telemed e-Health. 2016;22:246-50.

4. Farahani N, Pantanowitz L. Overview of telepathology. Surg Pathol Clin. 2015;8:223-31.

5. Şenel E, Demir E, Alkan RM. Bibliometric analysis on global Behçet disease publications during 1980-2014: Is there a Silk Road in the literature? J Eur Acad Dermatology Venereol. 2017;31:51822.

6. Vodovnik A. Distance reporting in digital pathology: A study on 950 cases. J Pathol Inform. 2015;6:18.

7. GunnMap. GunnMap 2 [WWW Document]. URL http://lert. co.nz/map/ [accessed on 12 January 2018].
8. Vosviewer. VOSviewer - Visualizing scientific landscapes [WWW Document]. 2017.URL http://www.vosviewer.com/ [accessed on 22 October 2017].

9. United Nations. Country Classification. In: World Economic Situation \& Prospects for 2019 | Economic Analysis \& Policy Division. New York: 2019;143-50.

10. Perednia DA, Allen A. Telemedicine technology and clinical applications. JAMA J Am Med Assoc. 1995;273:483-8.

11. Weinstein RS, Graham AR, Richter LC, Barker GP, Krupinski EA, Lopez AM, Erps KA, Bhattacharyya AK, Yagi Y, Gilbertson JR. Overview of telepathology, virtual microscopy, and whole slide imaging: Prospects for the future. Hum Pathol. 2009;40:1057-69.

12. Lee JJ, English JC. Teledermatology: A Review and update. Am J Clin Dermatol. 2018;19:253-60.

13. Rivera-Ruiz M, Cajavilca C, Varon J. Einthoven's string galvanometer: The first electrocardiograph. Texas Hear Inst J 2008;35:174-8

14. Gershon-Cohen J, Cooley AG. Telognosis. Radiology. 1950;55:582-7.

15. Wittson CL, Benschoter R. Two-way television: Helping the Medical Center reach out. Am J Psychiatry. 1972;129:624-7.

16. Weinstein RS. Prospects for telepathology. Hum Pathol. 1986;17:433-4.

17. Jara-Lazaro AR, Thamboo TP, Teh M, Tan PH. Digital pathology: Exploring its applications in diagnostic surgical pathology practice. Pathology. 2010;42:512-8.

18. Vergani A, Regis B, Jocollé G, Patetta R, Rossi G. Noninferiority diagnostic value, but also economic and turnaround time advantages from digital pathology. Am J Surg Pathol. 2018;42:841-2.

19. Şenel E. Health and religions: A bibliometric analysis of health literature related to Abrahamic Religions between 1975 and 2017. J Relig Health. 2018;57:1996-2012.

20. Haustein S. Multidimensional journal evaluation: analyzing scientific periodicals beyond the impact factor. De Gruyter/ Saur, 2012 URL http://crc.ebsi.umontreal.ca/en/publications/ multidimensional-journal-evaluation-analyzing-scientificperiodicals-beyond-the-impact-factor-2/ [accessed on 17 January 2018].

21. Della Mea V. 25 years of telepathology research: A bibliometric analysis. Diagn Pathol. 2011;(6)1:26. 